\title{
Response to E.R. Alexander's Comment on "The Role of Knowledge in Planning"
}

Yvonne Rydin

Bartlett School of Planning, University College London, England

I am most grateful to Ernest Alexander for taking the time to write his comment on my paper and for the perceptive points that he raises. I hope that this is a sign that the issue of knowledge and planning is receiving renewed attention. Perhaps I should explain why I consider this particularly important at the current moment. As I write, the Intergovernmental Panel on Climate Change have just issued their most recent report, synthesising previous reports and re-emphasising again the importance of both adapting to established climate change and seeking to mitigate further change. If planning is to play a role in this societal task, then it needs to enhance its knowledge base. However, rather that just revert to a modernist stance on the need for planners to develop substantive expertise relevant to climate change, I wished to advance a theoretical position on knowledge and planning which would be fit for purpose within the climate change agenda.

For that reason, I have retained a position in which knowledge is not attached to the planner but rather engagement over knowledge claims is linked to the institutional arrangements of the planning process. I appreciate that this may well mean that I am less able to comment on the content of the planning syllabus but I think it does have implications for how we design our planning institutions and, by implication, the 
skills that we need to imbue in planners through education, i.e. the skills to be able to cope within these institutions.

I would like to clarify a couple of points that Ernest Alexander's helpful comment highlighted. First, I do not wish to suggest that planning processes should only be about handling knowledge claims. Rather I see a variety of claims being disputed and tested within planning arenas; knowledge claims are one sort of claim but one that seems to have been underemphasised within postmodern planning theory. I do wish to emphasis that any planning situation involves a variety of knowledge claims alongside other claims and I would rather suggest that challenging and testing all sorts of knowledge claims is a feature of all forms of planning, at all scales and levels.

My intention in emphasising the causal basis to knowledge claims was to identify testability and refutability as key characteristics of such claims. And I agree that this does also apply, if more implicitly, to informational forms. I also agree that I have included experiential knowledge as a form of knowledge claim while also arguing that there is a difference between experiential stories or appeals to emotion and such knowledge claims. Here I hoped to rescue such stories and appeals from having to be seen as knowledge; I wished to suggest that such stories and appeals can have their forms of claim within the planning process. Indeed experiential stories may have a knowledge dimension as well as, say, a legitimacy claim. But the different types of claim play different within planning exchanges. I should also point out that I use the term normative knowledge rather differently to Alexander: for me this refers to a view of what the future could and should be like involving a causal understanding of what 
is possible; Alexander uses this term to mean understanding (by the planner) of values, needs and problems.

It was particularly helpful (if damaging to my argument) for Alexander to point out the infinite regress potentially involved in my use of the word 'appropriate' to suggest how knowledge claims may fit into particular planning situations and come to be accepted as valid within those situations. I think that there are two different aspects of planning engagements between actors here. On the one hand, there is the acceptance of the relevance of the knowledge claim to the issue at hand and the arguments and debates over whether a particular claim is relevant or not. Are arguments about the safety of an installation relevant to the planning decision? What about evidence on market demand for a development? These are contested areas.

The other aspect is the ability of the knowledge claim to be tested, to be warrantable. This may be unrecognised or remain implicit within many planning situations. But I wish to argue that the appropriateness of a knowledge claim depends on its ability to be tested. Otherwise it should be entertained as a knowledge claim and influence planning debates on the basis that it constitutes knowledge. For it is in such testing that the knowledge is co-constructed by the social process of planning and material reality.

Within planning as currently practiced, one of the great limitations on the testing of knowledge claims is the lack of monitoring mechanisms and the reliance instead on pre-development assessments. However, the material world can catch up with us. If we do not engage with the knowledge claims regarding climate change and flood risk 
in planning developments, say, then the experience of increasing numbers of householders will highlight that these were warrantable claims. Would it not be better to ensure that such claims are debated within appropriate planning arenas? To my mind collaborative modes of postmodern planning do not sufficiently allow for this. My hope was to propose an alternative, still post-modern planning theory which would.

979 words 